\title{
An Analysis of VANET Topology Based Routing Approach on Various Parameters
}

\author{
Kriti Jaiswal $^{\# 1}$, Om Prakash ${ }^{* 2}$ \\ ${ }^{\# *}$ Department of Computer Science \& Engineering, United College of Engineering \& Research \\ Allahabad, U.P, India
}

\begin{abstract}
Vehicular ad hoc network (VANET) is a peculiar subclass of mobile ad-hoc network (MANET) that has the potential in improving road safety and in providing travellers comfort. Currently it has gained an important part of interest of researchers and become very popular. One of the main challenges in VANET is of searching and maintaining an effective route for transporting data information. Hence, an analysis on routing protocols based on various parameters of VANET is a necessary issue in communication. Simulation tools has been preferred over outdoor experiment because it simple, easy and cheap. VANET requires that a traffic \& network simulator should be used together to perform the test. In this paper, we present brief analysis of routing protocols and ending up with the most appropriate simulation tools to simulate VANET protocols and application.
\end{abstract}

Keywords: Mobile ad-hoc network (MANET), Vehicular ad-hoc network (VANET), Routing Protocols, Performance Parameter, and Simulators etc.

\section{Introduction}

Vehicular Ad Hoc Network (VANET) provides wireless communication among vehicles (V2V) or vehicle to road side unit (RSU) forming vehicle to infrastructure communication (V2I) based on the VANET architecture \& communication domain [1]. A vehicle in VANET is considered to be an intelligent mobile node capable of communicating with its neighbours and other vehicles in the network [2]. The performance of communication depends on how better the routing takes place in the network based on parameters used and this is done through using the VANET simulator. Routing of data depends on the routing protocols being used in network. VANET has no. of characteristics such as: self organized and distributed network, high mobility and rapid changing (dynamic) topology, geographic position available, mobility modelling and prediction, hard delay constraints, no power constraint [3],[4], providing safe driving, improving passenger comfort and enhancing traffic efficiency, variable network density, large scale network, high computational ability and so on.

The complete paper is organized as follows. In Section 2, we describe the related work for VANETs. In Section 3, we describe the parameters for the performance which utilized in our work. In Section 4, we give a comparative analysis of various topology based routing protocols of VANET. In Section 5, we give a review of simulators of VANET. In Section 6, we describe the application of VANET. Section 7, provides our concluding remarks.

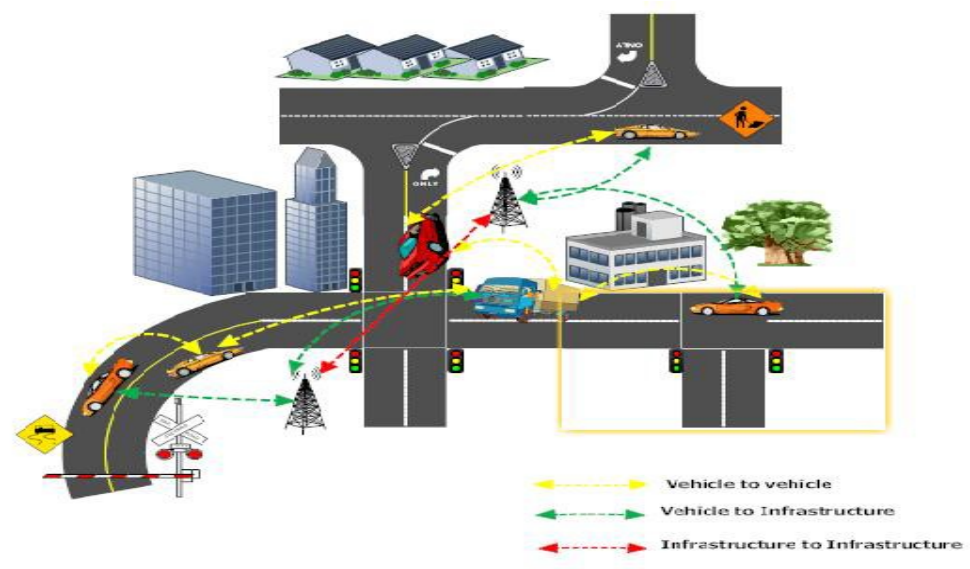

Fig. 1 shows the VANET Communication

\section{Related Work}

Vehicular Ad hoc networks (VANETs) are a special type of mobile ad hoc networks; where vehicles are simulated as mobile nodes. Vehicle to vehicle communication (V2V) has two types of communication: one hop communication (direct vehicle to vehicle communication), and multi hop communication (vehicle relies on 
other vehicles to retransmit). VANET also has special characteristics that distinguish it from other mobile ad hoc networks; the most important characteristics are: high mobility, self-organization, distributed communication, road pattern restrictions, and no restrictions of network size, all these characteristics made VANETs environment a challenging for developing efficient routing protocols [3], [4]. The main goal for routing protocol is to provide optimal paths between network nodes via minimum overhead. Many routing protocols have been developed for VANETs environment, which can be classified in many ways, according to different aspects; such as: protocols characteristics, techniques used, routing information, quality of services, network structures, routing algorithms, and so on [5].

Vehicular Ad hoc Network (VANET) is aimed to support safety, traffic monitoring and comfort related services [1]. Though functioning of the network closely resembles with that of MANET, its high speed mobility and unpredictable movement characteristics are the key contrasting feature from that of MANET. This similarity nature suggests that the prevailing routing protocol of MANET is very much applicable to VANET [17].

\section{Parameters for Performance}

To evaluate the performance of routing protocol, performance parameters are considered:

\section{A. Packet Delivery Ratio (PDR)}

Ratio of data packets reached to the packets sent by the traffic sources. It is the fraction of generated packets by received packets. That is, the ratios of packets received at the destination to those of the packets generated by the source. As of relative amount, the usual calculation of this system of measurement is in percentage (\%) form. Higher the percentage, more privileged is the routing protocol.

\section{B. Routing Load}

Total no. of packets required to construct and maintain routes between source and destination mobile nodes.

\section{End-to-End (E2E) Delay}

It computes average delay in receiving correct data packets generated by the sources [6]. It is the calculation of typical time taken by packet (in average packets) to cover its journey from the source end to the destination end. The classical unit of this metric is millisecond (ms). For this metric, lower the time taken, more privileged the routing protocol is considered.

\section{Maximum Simulation Time (in seconds)}

It is the total duration of the simulation.

\section{E. Received Packets}

It measures the number of received packets.

\section{F. Reception Time of the First Packet}

The parameter informs us about the time it takes to establish the connection for each of the protocols.

\section{G. Dropped Packets}

It represents those packets which fail to reach their destination.

\section{H. No. of Hopes}

It refers to the number of hopes that the packet need to reach their destination.

\section{Comparative Analysis of topology based routing protocol}

Routing in MANETs and VANETs is complex since mobility causes frequent topology changes and requires more robust and flexible mechanism to search for routes and maintain them. When the network nodes move, the established paths may break and the routing protocols must dynamically search for other feasible routes. With a changing topology, even maintaining connectivity is very difficult. Therefore, routing protocols for MANETs and VANETs must deal with the following premises:

- Distributed Operation: since is the basis of MANETs and VANETs.

- Signalling Reduction: allowing conserving battery capacity and enhancing network efficiency.

- Keeping the Routes Loop Free: in order to avoid packets flowing indefinitely on the network and network congestion.

- Reduced Processing Time: aiming to save node's resources. 
- Management of Asymmetric Links: caused by different power levels among mobile nodes and other factors such as terrain condition.

Many protocols have been proposed for VANETs. The routing protocols fall into five major categories of topology-based, position-based, cluster based, geocast routing and Broadcast routing but our analysis is based on topology based routing protocols which can be divided into three categories: proactive, reactive and hybrid [7]. These routing protocols use links information that exists in the network to perform packet forwarding. In other words, each node should be aware of the network layout, also should able to forward packets using information about available nodes and links in the network.

\section{A. Proactive (Table-Driven) Routing Protocols}

It maintains routes to all destinations, regardless of whether or not these routes are needed [9]. The advantage of proactive routing protocol is that there is no route discovery since the destination route is stored in the background, but the disadvantage of this protocol is that it provides low latency for real time application [8]. A table is constructed and maintained within a node. So that, each entry in the table indicates the next hop node towards a certain destination. It also leads to the maintenance of unused data paths, which causes the reduction in the available bandwidth. The various types of proactive routing protocols are: OLSR [16], LSR, FSR [11], and WRP.

\section{B. Reactive (On-Demand) Routing Protocols}

Reactive routing opens the route only when it is necessary for a node to communicate with each other [10]. It maintains only the routes that are currently in use; as a result it reduces the burden in the network. Reactive routing consists of route discovery phase in which the query packets are flooded into the network for the path search and this phase completes when route is found, that the source node starts a route discovery process, if it needs a non existing route to destination, it does this process by flooding the network by route request message. After the message reaches the destination node, this node will send a route reply message back to the source node using unicast communication [17]. The various types of reactive routing protocols are AODV [12], DSR [13] and TORA [14].

\section{Hybrid Routing Protocols}

Hybrid routing protocols combine the proactive and reactive routing approaches. It aims to minimize the proactive routing protocol control overhead and reduces the delay of the route discovery process within on demand routing protocols. They divide the network into routing zones, so that it will be used proactive routing schemes for intra-zones routing issues and reactive routing schemes for inter-zones routing issues. Each node divides the network into two regions: inside and outside regions; it uses a proactive routing mechanism to maintain routes to inside region nodes and using a route discovery mechanism to reach the outside region nodes. The most representative hybrid routing protocol is ZRP (Zone Routing Protocol) [15].

Table I Comparison Of Topology Based Routing Protocols On Vanet Environment

\begin{tabular}{|c|c|c|c|c|c|c|c|c|}
\hline Parameter & $\begin{array}{c}\text { Forwa- } \\
\text { rding } \\
\text { Strate- } \\
\text { Py }\end{array}$ & $\begin{array}{c}\text { Scenari } \\
\text { Protocols }\end{array}$ & $\begin{array}{c}\text { Routing } \\
\text { Maintena } \\
\text {-nce }\end{array}$ & $\begin{array}{c}\text { Infrastru } \\
\text {-cture } \\
\text { Require- } \\
\text { ment }\end{array}$ & $\begin{array}{c}\text { Recover } \\
\text { y } \\
\text { Strategy } \\
\text { hop }\end{array}$ & $\begin{array}{c}\text { Digital } \\
\text { Map }\end{array}$ & $\begin{array}{c}\text { Control } \\
\text { Packet } \\
\text { Overhea } \\
\text { d }\end{array}$ & $\begin{array}{c}\text { No of } \\
\text { Retrans- } \\
\text { mission }\end{array}$ \\
\hline FSR & $\begin{array}{c}\text { Multi } \\
\text { hop }\end{array}$ & Urban & Proactive & No & $\begin{array}{c}\text { Multi } \\
\text { hop }\end{array}$ & No & High & Less \\
\hline AODV & $\begin{array}{c}\text { Multi } \\
\text { hop }\end{array}$ & Urban & Reactive & No & $\begin{array}{c}\text { Store } \\
\text { and } \\
\text { Fonvard }\end{array}$ & No & Low & Less \\
\hline DSR & $\begin{array}{c}\text { Multi } \\
\text { hop }\end{array}$ & Urban & Reactive & No & $\begin{array}{c}\text { Store } \\
\text { and } \\
\text { Forward }\end{array}$ & No & Low & Less \\
\hline TORA & $\begin{array}{c}\text { Multi } \\
\text { hop }\end{array}$ & Urban & Reactive & No & $\begin{array}{c}\text { Store } \\
\text { and } \\
\text { Forward }\end{array}$ & No & Low & Less \\
\hline ZRP & $\begin{array}{c}\text { Multi } \\
\text { hop }\end{array}$ & Urban & Hybrid & No & $\begin{array}{c}\text { Multi } \\
\text { hop }\end{array}$ & No & Moderate & Less \\
\hline
\end{tabular}

\section{Simulator Analysis}

The network's performance can be best judged through the deployment of a simulation. It is important to evaluate the performance of any network in order to highlight any issues that may exists; the most appropriate 
way to accomplish this task is therefore to deploy simulations that provide the closest results to real world observations.

There are two aspects of simulating VANET: one is the traffic simulation and other is network simulation [18]. The traffic simulation aids in creating traces of urban mobility model; this information is fed into the network simulation. The network simulation builds topologies between the nodes and vice versa. Traffic simulators are used for transportation and traffic engineering. Various simulation tools have been used to evaluate and simulate the performance of routing protocols in VANET [1].

\section{A. Networking Simulators}

Networking simulators are used to evaluate network protocols and application in a variety of conditions. Compared to the time and cost involved in setting up real hardware they permit users to test and deploy new protocols in a controlled way. There are many networking simulators currently available. Some of them are open-source while others are commercial. The most popular open source ones are ns-2 [19], GloMoSim [20], OMNet++, JiST/SWANS. Important commercial ones are OPNET and QualNet.

\section{B. Traffic Simulator}

It generates realistic traffic traces for use as input to a network simulator. Traffic simulators generate traces containing node locations and timing details. Examples of widely used open source traffic simulators are VanetMobiSim [21], SUMO, MOVE, STRAW and CityMob. Commercial one is PARAMICS.

\section{VANET Simulators}

The VANET simulators are integrated frameworks of network and traffic simulators. Examples are NCTUns, TraNS, and GrooveNet.

TABLE II Comparison Of Networking Simulator On VANET Environment

\begin{tabular}{|c|c|c|c|c|c|c|}
\hline & NS-2 & GloMoSim & OMNet++ & JiST/SWANS & OPNET & QualNet \\
\hline Type of License & $\begin{array}{l}\text { Open } \\
\text { Source }\end{array}$ & Open Source & Open Source & Open Source & Commercial & Commercial \\
\hline $\begin{array}{l}\text { Library of Known } \\
\text { Protocols }\end{array}$ & Yes & Yes & Yes & Yes & Yes & Yes \\
\hline $\begin{array}{c}\text { Good } \\
\text { Documentation }\end{array}$ & Yes & No & No & No & Yes & No \\
\hline Large Network & No & Yes & Yes & Yes & Yes & Yes \\
\hline GUI & Yes & Yes & Yes & Yes & Yes & Yes \\
\hline Ease of Setup & Easy & Easy & Moderate & Hard & Yes & Moderate \\
\hline Ease of Use & Easy & Easy & Moderate & Hard & & Moderate \\
\hline Portability & Yes & Yes & Yes & Yes & Yes & Yes \\
\hline GUI & Yes & Yes & Yes & Yes & Yes & Yes \\
\hline $\begin{array}{c}\text { Continuous } \\
\text { Development }\end{array}$ & NS-3 & No & Yes & Yes & & Yes \\
\hline Scalability & Poor & High & High & High & & High \\
\hline $\begin{array}{c}\text { Programming } \\
\text { Language }\end{array}$ & $\mathrm{C}++$ & $\mathrm{C}$ & $\mathrm{C}++$ & Java & & $\mathrm{C}++$ \\
\hline
\end{tabular}

TABLE III Comparison Of Traffic Simulator On VANET Environment

\begin{tabular}{|l|l|l|l|l|l|l|}
\hline & VanetMobiSim & SUMO & MOVE & STRAW & CityMob & PARAMICS \\
\hline Type of License & Open Source & Open Source & Open Source & Open Source & Open Source & Commercial \\
\hline GUI & Yes & Yes & Yes & Yes & Yes & Yes \\
\hline $\begin{array}{l}\text { Continuous } \\
\text { Development }\end{array}$ & No & Yes & No & No & Yes \\
\hline Ease of Setup & Moderate & Moderate & Easy & Moderate & Easy & Easy \\
\hline Ease of Use & Moderate & Hard & Moderate & Moderate & Easy & Moderate \\
\hline Real Map & Yes & Yes & Yes & Yes & No & Yes \\
\hline User Defined Map & Yes & Yes & Yes & No & No & Yo \\
\hline Examples & Yes & Yes & Yes & No & Yes & Yos \\
\hline $\begin{array}{l}\text { Random } \\
\text { Mobpoint }\end{array}$ & Yes & Yes & Yes & No & Yes & Yes \\
\hline $\begin{array}{l}\text { NS-2 Trace } \\
\text { Support }\end{array}$ & Yes & No & Yes & No & No & No \\
\hline $\begin{array}{l}\text { GloMoSim Trace } \\
\text { Support }\end{array}$ & Yes & No & Yes & Yes & No & Yes \\
\hline $\begin{array}{l}\text { OMNet++ } \\
\text { Swans Trace } \\
\text { Support }\end{array}$ & Yes & Yes & Yes & No & Yo & No \\
\hline QualNet Trace & Yes & No & No & \\
\hline
\end{tabular}




\begin{tabular}{|l|l|l|l|l|l|l|}
\hline Support & & & & & & \\
\hline $\begin{array}{l}\text { Import Different } \\
\text { Formats }\end{array}$ & Yes & Yes & Yes & No & No & Yes \\
\hline $\begin{array}{l}\text { XML Based } \\
\text { Support }\end{array}$ & Yes & No & No & No & No & \\
\hline
\end{tabular}

TABLE IV Comparison of VANET Simulator

\begin{tabular}{|c|c|c|c|}
\hline & NCTUns & TraNS & GrooveNet \\
\hline Type of License & Version 7 is not & Open Source & Open Source \\
\hline GUI & Yes & Yes & Yes \\
\hline $\begin{array}{c}\text { Continuous } \\
\text { Development }\end{array}$ & Yes & Yes & Yes \\
\hline Output & NS-2 & NS-2 & GrooveNet \\
\hline Mobility Generator & NCTUns & SUMO & Good \\
\hline User Friendly & Moderate & Good & Moderate \\
\hline Ease of Setup & Hard & Moderate & Hard \\
\hline Ease of Use & Easy & Moderate & Street View \\
\hline Programming Language & C++ & Java & \\
\hline Topology View & User Defined & Google Earth & \\
\hline
\end{tabular}

\section{Applications}

V2V and V2I communications allows the development of a large number of applications and can provide a wide range of information to drivers and travellers. A VANET communication platform allows an enormous variety of applications aimed at administration, companies, drivers and people in the vehicle.

\section{A. Safety Related Applications}

Safety-related applications are the most important kind of applications for VANETs due to its main objective: decrease of injuries and deaths due to vehicle accidents. These applications use the wireless communication between vehicles or between vehicles and infrastructure, in order to improve road safety and avoid accidents [1]. Electronic sensors in each car can detect abrupt changes in path or speed and send an appropriate message to neighbours.

- Intersection Collision Avoidance

- Cooperative Collision Avoidance

- Cooperative Driver Assistance System

- Public Safety

- Sign Extension

- Vehicle Diagnostics and Maintenance

- Information from others vehicles

- Policing \& Enforcement and so on.

\section{B. Comfort Applications}

The general aim of these applications is to improve passenger comfort and traffic efficiency. That could include nearest POI (Points of Interest) localization, current traffic or weather information and interactive communication. Passenger can play online games, access the internet and send or receive instant messages while the vehicle s connected to the infrastructure network.

- Optimum route calculation with real-time traffic data

- Data Transfer

- Software Update/Flashing

- Automatic Parking and so on.

C. Applications for Administration:

- Vehicle identification

- Electronic Toll Collection

- Parking Lot Payment

- Traffic Information and so on.

\section{Conclusion}

Vehicular Ad-Hoc Network is an emerging and promising technology. Routing is an important component in vehicle-to-vehicle (V2V) and infrastructure-to-vehicle (I2V) communication. This paper has 
presented a comparative analysis of topology based routing protocols. Hence, an analysis of VANET protocols, comparing the various features is absolutely essential to come up with new proposals for VANET. The performance of VANET routing protocols depend on various parameters. It also presented an analysis of networking, traffic and VANET simulators. This paper also tells the application of the VANET. This can serve as a quick reference for researchers who want to do research in VANETs. We hope that the instrument presented in this paper to be useful and helpful to students and researchers in this field.

\section{Acknowledgment}

This work is the result of good support and guidance with facilities, which were provided to us by the Department of Computer Science and Engineering. The authors would like to express their deepest gratitude to the faculty of United College of Engineering \& Research, Allahabad, India for his guidance, support, and contribution for this paper. At last but not least, I want to thank all the members of the Department who helped me towards the completion of my paper.

\section{References}

[1] Saif Al-Sultan, Moath M. Al-Doori, Ali H. Al-Bayatti, Hussien Zedan, “ A comprehensive survey on vehicular Ad Hoc network”, Journal of Network and Computer Applications, journal.

[2] Sherali Zeadally, Ray Hunt, Yuh-Shyan Chen, Angela Irwin, Aamir Hassan, "Vehicular ad hoc networks (VANETS): status, results, and challenges", Telecommun Syst DOI 10.1007/s11235-010-9400-5.

[3] Yue Liu, Jun Bi, Ju Yang, "Research On Vehicular Ad Hoc Networks", 978-1-4244-2723-9/09/\$25.00 (C2009 IEEE.

[4] Sivasakthi M, Suresh S.R, "Research on vehicular ad hoc networks (VANETs): An Overview", Int. Journal of Applied Sciences and Engineering Research, Vol. 2, No. 1, 2013, ISSN 2277-8442.

[5] Marwa Altayb, Imad Mahgoub, “A Survey of Vehicular Ad Hoc Networks Routing Protocols", International Journal of Innovation and Applied Studies ISSN 2028-9324 Vol. 3 No. 3 July 2013, pp. 829-846.

[6] Laiq Khan, Nohman Ayub and Aamir Saeed, "Anycast Based Routing in Vehicular Adhoc Networks (VANETS) using Vanetmobisim", World Applied Sciences Journal 7 (11): 1341-1352, 2009 ISSN 1818-4952.

[7] Mrs. Uma Nagaraj, Ms. Poonam P. Dhamal, "Performance Comparison of AODV, AOMDV, OLSR, DSR and GSR Routing Protocols in VANET", UACEE International Journal of Advances in Computer Networks and its Security - Volume 2: Issue 2 [ISSN 2250 - 3757 ].

[8] Mushtak Y. Gadkari, Nitin B. Sambre, "VANET: Routing Protocols, Security Issues and Simulation Tools", IOSR Journal of Computer Engineering (IOSRJCE), ISSN: 278-0661 Volume 3, Issue 3 (July-Aug. 2012), PP 28-38.

[9] Bilal Mustafa, Umar Waqas Raja, (June-2010) "Issues of Routing in VANET", Thesis no: MCS-2010-20, Sweden.

[10] Sandhaya Kohli, Bandanjot Kaur, Sabina Bindra, (Apr 2010) "A Comparative study of Routing Protocols in VANET", RIMT-IET,10.

[11] M. Gerla, X.Hong, G.Pei, "Fisheye State Routing Protocol (FSR)", IETF Internet Draft, work in progress, draft-ietf-manet-fsr-03.txt, July 2002 .

[12] C. Perkins, E. Belding-Royer, and S.Das, "Ad Hoc On-Demand Distance Vector (AODV) Routing”, RFC 3561, N/w Working Group, 2003.

[13] D. Johnson, B.D.A. Maltz, and Y.C. Hu, "The Dynamic Source Routing Protocol for Mobile Ad-Hoc Networks (DSR)", draft-ietf-manetdsr-10.txt, 2004.

[14] V. Park, S. Corson, “Temporally Ordered Routing Algorithm (TORA) Version 1 Functional Specification”, IETF internet draft, work in progress, draft-ietf-manet-tora-spec-04.txt, 2001.

[15] Z. J. Haas, "The Zone Routing Protocol (ZRP) for ad-hoc networks", Internet Draft, Nov.1997.

[16] T. Clausen, et al., "Optimized Link State Routing Protocol (OLSR)”, RFC 3626, Network Working Group, Oct. 2003.

[17] M. Abolhasn, T. Wysocki and E. Dutkiewicz, "A review of routing protocols for mobile ad hoc networks", Ad Hoc Networks 2, Elsevier, pp. $1-22,2004$.

[18] Sabih ur Rehman, M. Arif Khan, Tanveer A. Zia and Rashid H. Khokhar, "A Synopsis of Simulation and Mobility Modeling in Vehicular Ad-hoc Networks (VANETs)", IOSR Journal of Computer Engineering (IOSR-JCE), e-ISSN: 2278-0661, p- ISSN: 2278-8727Volume 15, Issue 2 (Nov. - Dec. 2013), PP 01-16.

[19] NS2, http://www.isi.edu/nsnam/ns/.

[20] GloMoSim, Available at http://pcl.cs.ucla.edu/projects/glomosim/obtaining-glomosim.html

[21] Haerri, F.M. et al., 2007. Vehicle Mobility Simulation for VANETs: in Proceedings of the $40^{\text {th }}$ Annual Simulation Symposium (ANSS 2007), Norfolk, Virginia, March 2007.

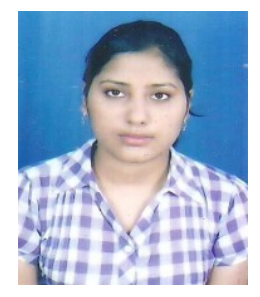

Kriti Jaiswal received the Bachelor of Technology (B.Tech) degree in Computer Science \& Engineering from Allahabad Institute of Engineering \& Technology, Allahabad, India in 2012 and currently pursuing Master of Technology (M.Tech) in Computer Science \& Engineering from United College of Engineering \& Research, Allahabad, India. Her research interests include wireless ad-hoc networks, performance evaluation of systems and networks. The author has key interest in the field of computer networks, information security, ad-hoc networks and mobile computing.

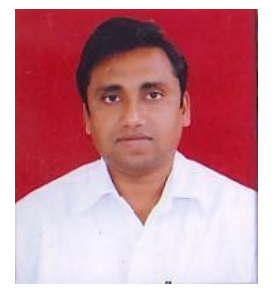

Om Prakash received the Bachelor of Technology (B.Tech) degree in Computer Science \& Engineering and Master of Technology (M.Tech) in Computer Science \& Engineering. Currently he is working as an Assistant Professor in Department of Computer Science \& Engineering of United College of Engineering \& Research, Allahabad, India. He has more than 10 years working experience in the field of trashing and research in computer science area. 